\title{
Photoluminescent nanosensors capped with quantum dots for high-throughput determination of trace contaminants: Strategies for enhancing analytical performance
}

\author{
Weijun Kong ${ }^{\mathrm{a} \dagger}$, Xihui Yang ${ }^{\mathrm{a}, \mathrm{b}, \mathrm{c} \dagger}$, Meihua Yang ${ }^{\mathrm{a}^{*}}$, \\ Hao Zhou ${ }^{\mathrm{b}}$, Zhen Ouyang ${ }^{\mathrm{c}}$, Ming Zhao ${ }^{\mathrm{c}}$ \\ ${ }^{\mathrm{a}}$ Institute of Medicinal Plant Development, Chinese Academy of Medical Science, Peking Union \\ Medical College, Beijing 100193, China \\ ${ }^{\mathrm{b}}$ Chia Tai Tianqing Pharmaceutical Group Co., Ltd., Nanjing 210023, China \\ ${ }^{c}$ School of Pharmacy, Jiangsu University, Zhenjiang 212013, China
}

* Corresponding author. E-mail: yangmeihua15@hotmail.com, Tel.: +86 1057833277; Fax: +86 1062896288;

$\uparrow$ These authors contributed equally to this work. 


\begin{abstract}
High-throughput determination of trace contaminants has attracted a great deal of attention due to their high toxicity, hyperstability and ultra-low level. Among various analytical methods developed during the past few decades, nanosensoring techniques have become increasingly popular due to their potential for portable, rapid and real-time detection. Quantum dots (QDs) are colloidal semiconductor nanocrystals with excellent photoluminescent properties, high quantum yields and high resistance to photobleaching. Recently, QD-based photoluminescent nanosensing (plnanosensing) techniques have provided new advances in the field of contaminant determination for environmental monitoring and food quality control. This review focuses on the improvements in the analytical performances of QD-based plnanosensing techniques in order to achieve on-site rapid screening of multiple contaminants. Critical factors along with some difficulties in high-throughput determination of trace contaminants are summarized. Furthermore, the main strategies for enhancing the analytical performance of QD-based plnanosensors based on the characteristics and difficulties of trace analysis are highlighted. Finally, we discuss the difficulties in association with the use of QD-based optosensors in trace analysis and the prospective applications of this novel analytical technique in the future.
\end{abstract}

Keywords: Quantum dots; Plnanosensors; Trace contaminants; High-throughput analysis; Analytical performance enhancement; Environmental and food safety 


\section{Introduction}

Over the past few decades, a large crop of exogenous harmful materials (mycotoxins, pesticides, heavy metals, etc.) regarding their contamination in complex matrices such as foods, feeds and medicinal plants have received considerable attention due to their high occurrence in these matrices and potential toxicological risks to human and animal health and the environment, as well as the enormous challenges involved in quantifying low concentrations at ppm $(\mathrm{mg} / \mathrm{kg})$, ppb $(\mu \mathrm{g} / \mathrm{kg})$ or ppt $(\mathrm{ng} / \mathrm{kg})$ levels. Current analytical methods for these materials are largely restricted to laboratory instrumental analysis [1, 2] and enzyme-linked immunosorbent assay (ELISA) [3, 4]. The former requires rigorous sample preparation steps prior to analysis, including extraction, clean-up, enrichment and possible derivatisation [5] in order to improve the sensitivity and selectivity by eliminating interferences with the matrix. However, these essential steps may also decrease the analytical accuracy of various techniques due to the potential loss of trace contaminants and the increase in both cost and time associated with professional operation. In the case of ELISA, specific reactions between enzyme and antibody may face challenges of poor tolerance due to the complexity of the matrices and therefore easily produce cross-reactions and false-positive results. Therefore, convenient, ultra-sensitive and -fast analytical platforms that do not require complex preparation steps may play a significant role in multiplex high-throughput screening and on-site monitoring of trace contaminants.

Despite the fact that traditional optical analytical techniques have been widely applied for decades as potential analytical tools for the detection of trace contaminants, the matrix effects (enhancement/suppression) in complex samples for ultratrace contaminants have not been well studied. Recently, photoluminescence (PL) properties of colloidal semiconductor nanocrystals or quantum dots (QDs) in sensors have led to the development of photoluminescent nanosensors (plnanosensors) for trace determination of multiple targets [6-8]. QDs are monodisperse crystalline 
clusters with physical dimensions that are smaller than the bulk-exciton Bohr radius in the range of $1-20 \mathrm{~nm}$ and contain anywhere from 100 to 100,000 atoms per nanoparticle [9]. Multidisciplinary applications of QDs have been studied due to their unique electro-optical properties, including narrow and symmetric size-tunable PL spectra $(25-40 \mathrm{~nm})$, broad absorption spectra, high quantum yields, large and effective stokes shifts and high resistances to photobleaching and chemical degradation. In addition, multi-functionalization of QDs has been achieved for bioconjugating bio/chem-ligands $[10,11]$. However, multiplex high-throughput determination using QDs remains challenging due to the coexcitation of multiple QD emission wavelengths by a single excitation wavelength, since the tunability of their PL emission bands depends on both the nanoparticle size (1-12 $\mathrm{nm})$ and composition, which is determined by atoms in groups II-VI, III-V or IV-VI (e.g., CdSe, CdTe, InP, $\mathrm{PbS}$ and $\mathrm{CdSe} / \mathrm{ZnS}$ ) [12]. Additionally, QDs can be applied in many other techniques, such as biosensors, intelligent gene chips and nanotechnology, etc, as well as a large crop of fields, such as chemistry, microbiology, and biochemistry, to enhance specificity, sensitivity and detection speed [13-17].

Herein, we describe in detail the current status and advances in the field of QD-based portable plnanosensors for the convenient and rapid high-throughput determination of trace contaminants, allowing for enhanced analytical performance and the possibility of on-site rapid screening. In this review, the critical factors and difficulties, together with the requirements and solutions in association with determination levels of trace contaminants in foods and the environment are summarized. The main strategies for enhancing the analytical performance of QD-based plnanosensors in order to overcome these difficulties in trace determination are subsequently highlighted. Finally, future trends in the field of QD-based plnanosensors for monitoring trace contaminants are discussed (Fig. 1).

Fig. 1

\section{Characteristics of trace determination}


Despite the fact that trace contaminants, such as mycotoxins, pesticides, heavy metals, and polycyclic aromatic hydrocarbons, are present in samples at ppm, ppb or ppt level, they are still associated with the disruption of ecological systems, environment hazards and threats to human health. The maximum levels of these contaminants together with the performance criteria for analytical methods have been suggested by some related organizations, such as the European Union (EU) [18].

According to the guidelines introduced by these organizations and previous reports for high-throughput analysi of trace contaminants, sampling procedures must first be optimized in order to accurately and precisely predict contaminant levels depending on lot weight, since different parts within the same sample may possess various contamination levels. In general, homogeneous and representative samples are obtained by evaluating the sampling and analytical variability using a balanced nested design $[19,20]$.

Moreover, a more sensitive method with a lower limit of detection (LOD) and quantitation (LOQ) will balance the problems induced by the trace and ultra-trace levels through the introduction of an extra enrichment step [21] as well as the addition of a potential derivatization process in order to improve the performance of the analytical technique $[22,5]$.

Additionally, trace contaminants can be widely found in various matrices which possess enormous complexity and diversity in kinds and compositions and the contaminants will express correlations with the matrices. So, matrix effect should be evaluated to determine the reliability of the analytical method for trace determination, since signal response from contaminants can often be enhanced or suppressed by interference with constituents of the matrix, especially in the case of complex matrices such as agri-foods, medicinal plants and bio-products. Increasing the selectivity of analytical methods or adding an appropriate clean-up step can help eliminate or decrease the influence of matrix effects $[23,24]$ to avoid the false-positive results and accelerate analytical efficiency to bulk screening. 
Finally, due to the fact that most contaminatns are derived from enormous species with multifarious physical and chemical properties and usually co-occurred in the same matrix, multiplex high-throughput analysis has become the dominant issue for simultaneously screening matrices and contaminants as much as possible. Therefore, enhancing the selectivity and sensitivity of the analytical method is critical for the rapid determination of trace contaminants without any extra sample pretreatment steps.

\section{Strategies for enhancing the analytical performance of QD-based plnanosensors}

Owing to the previously mentioned characteristics of trace contaminants, the analytical performances of selected methods for high-throughput analysis must be validated in terms of selectivity, sensitivity, precision, accuracy, stability and repeatability. Selectivity and sensitivity are essential to the reliability and prospective applications of each analytical method. Due to their distinctive optical and bioconjugation properties, QD-based plnanosensors have been increasingly studied for high-throughput analysis of trace contaminants over the past few decades.

\subsection{Improving the selectivity of QD-based plnanosensors}

Matrix interferences commonly occur in trace analysis, which may lead to inaccurate results particularly in complex matrices. In this case, immobilization of biological materials (enzymes, antibodies, nucleic acids, microorganisms, cells, tissues, etc.) or chemical materials (supramolecular and host cross-linked polymers) as recognition receptors (their characteristics shown in Table 1), or QDs as signal transducers and amplifiers may minimize matrix effects and improve selectivity $[25,26]$.

\section{Table 1}

For bio-receptors, enzymes are the earliest bio-recognition elements in QD-based plnanosensors, and enhancing or suppressing the optical response of QDs based on the enzymatic reaction can determine the identities of various contaminants [27]. 
Furthermore, visualization of signal enhancement/suppression effects can be achieved in two ways. One way is based on the temporary inhibitory effect of enzymes by contaminants during the catalytic reaction of acetylcholinesterase (AChE) inhibited by organophosphorus pesticides [28-31] (Fig. 2A), the catalyzed oxidation of alcohol oxidase (AO) inhibited by $\mathrm{Cu}^{2+}$ [32], and during the catalytic reaction of horseradish peroxidase inhibited by phenols and $\mathrm{H}_{2} \mathrm{O}_{2}$ [33]. The other ways focuses on using contaminants as enzyme-substrates rather than inhibitors, such as the ability of oganophosphorus hydrolase $(\mathrm{OPH})$ to hydrolyze P-O, P-F, P-S, and P-CN bonds in oganophosphorus compounds to produce acids and alcohols. This reaction quenches the PL of QDs as the phenols are oxidized by tyrosinase (TRS) to form quinones [34-38]. Through the inner filter effect on fluorescence of QDs, a new type of 2,3-dihydroxybiphenyl 1,2-dioxygenase (BphC)-based fluorescent biosensor was developed for catechol and 2,3-dihydroxybiphenyl, which could be employed as a robust support for the construction of other enzyme-based biosensors [39] (Fig. 2B).

Fig. 2

Antibody or antigen-coated immunoassays have been widely used in QD-plnanosensors based on their specific recognition reactions with a $K$ level of $\mu \mathrm{M}$. Due to the abundant conjugation of amino acids in the protein, active esters, fragmented antibodies, avidin/protein $\mathrm{G}$ bridges, polyhistidine peptides, and various polyclonal/monoclonal antibodies $(\mathrm{pAb} / \mathrm{mAb})$ for the specific binding of contaminants, are considered to the ligands that preferentially bonded to QDs [11]. Furthermore, by optimizing the antibodies/QDs ratio, many assay formats have been developed, such as direct/indirect competition and sandwich modes. Indirect competition generally exhibits better selectivity and specificity compared to direct competition due to the fact that homogeneous immunoassays are known to be less sensitive than heterogeneous assays. The sandwich immunoassay needs double-antibodies and is therefore more suitable for analyzing pathogens rather than smaller sized contaminants since it requires immunogenicity by integrating carrier 
proteins (e.g. bovine serum albumin), which may decrease selectivity [40-42].

Nucleic acid-based QD-plnanosensors (also known as gene-plnanosensors) have recently emerged as materials with high affinities and specificities at a $K$ level of about nM. Gene-plnanosensors are formed by fabricating functional nucleic acid elements (DNAzymes, oligonucleotides, aptamers) as bioreceptors, which are selected by an in vitro selection process through the systematic evolution of ligands by exponential enrichment (SELEX) procedure. A novel electrochemical sensing system based on DNAzymes and rolling circle amplification has been developed for the detection of $\mathrm{Pb}^{2+}$. Due to dramatic signal amplification by numerous QDs, high sensitivity (7.8 pM) was achieved. More importantly, by taking advantage of the recognition process and cleavage efficiency of the metal ion dependent DNAzyme, the sensing system also demonstrated good selectivity against other divalent metal ions, such as $\mathrm{Zn}^{2+}, \mathrm{Mg}^{2+}, \mathrm{Cu}^{2+}, \mathrm{Mn}^{2+}, \mathrm{Hg}^{2+}$ and $\mathrm{Cd}^{2+}$. In addition, no masking agents are necessary, thereby simplifying the detection process [43]. By using aptamers, this method can also be expanded to detect mycotoxins [44, 45]. DNAzyme-stimulated chemiluminescence resonance energy transfer to $\mathrm{CdSe} / \mathrm{ZnS}$ QDs has been used for the detection of $\mathrm{Hg}^{2+}$ based on the $\mathrm{Hg}^{2+}$-induced self-assembly of nucleic acid subunits into the hemin/G-quadruplex catalytic label [46]. It is well known that ions can form stable complexes by bridging specific oligonucleotides (oligos). For example, $\mathrm{Hg}^{2+}$ ions can specifically bridge thymine bases $\left(\mathrm{T}-\mathrm{Hg}^{2+}-\mathrm{T}\right)$ and $\mathrm{Ag}^{+}$ions can specifically bridge cytosine bases $\left.\left(\mathrm{C}-\mathrm{Ag}^{+}-\mathrm{C}\right)\right]$. In previous studies, $\mathrm{T}$ - or C-rich modified QDs were introduced for the selective detection of $\mathrm{Hg}^{2+}$ and $\mathrm{Ag}^{+}$ions using an electron-transfer-quenching path, where $\mathrm{Hg}^{2+}$ and $\mathrm{Ag}^{+}$ions are used as inputs that activate logic gates to implement QDs as optical readout signals for logic gate operations [47]. The substitution of aptamers and QDs for antigens and AuNPs, respectively, led to the development of a fluorescent strip for monitoring ochratoxin A. This substitution effectively enhanced the specificity and sensitivity (LOD of 1.9 $\mathrm{ng} / \mathrm{mL}$ ) in complicated samples. The sensitivities and specificities of these fluorescent 
strips containing aptamer and QDs are improved compared to traditional gold immunochromatographic assays [48].

In the case of chem-receptors, supramolecular polymers receptors, such as azamacrocycles (Azas) [49], cyclodextrins (CDs) [50] and calixarenes [51-53], have been utsed to form molecular cavities in order to trap analytes on the surface of QDs. The recognition pattern is similar to the host-guest interaction and therefore can improve the detection selectivity in complex matrices through the synthesis and immobilization of the host and the guest and relevant QDs [54].

Molecularly imprinted polymers (MIPs) are host cross-linked materials that can be artificially synthesized by the induced copolymerization of functional and cross-linking monomers utsing analytes as templates. By taking advantages of their high specificities, chemical and thermal stabilities, and tolerance to organic reagents, MIPs have been successfully applied in QD-based plnanosensors. Due to the imprinting effect, diphenolic acid (DPA)-MIP-QDs optosensors have excellent selectivities and binding affinities of $K$ at $10180 \mathrm{M}^{-1}$ to tetrabromobisphenol $\mathrm{A}$ in water and soils by using DPA as dummy template molecule to graft onto the surface of $\mathrm{Mn}^{2+}: \mathrm{ZnS}$ QDs [55]. Due to weak interactions including van der Waals and hydrophobic forces, the $\mathrm{Mn}^{2+}: \mathrm{ZnS}$ QDs-based MIP composite nanospheres, which can be prepared via a facile and versatile ultrasonication-assisted encapsulation method, demonstrated excellent recognition selectivity of diazinon compared to similar chemical analogues (phoxim, primiphos-methyl, quinalphos, dichlofenthion, and fenthion) [56]. Moreover, MIPs-QDs were also fabricated in order to detect mycotoxins [57], pesticides [58, 59], 4-nitrophenol [60], and pentachlorophenol [61].

A turn-on fluorescent probe based on "ion-imprinted" sites and generated by ethylene diamine tetraacetic acid (EDTA)-etched-CdTe QDs has also been reported for the detection of $\mathrm{Cd}^{2+}$. In this probe, specific $\mathrm{Cd}^{2+}$ ionic imprinted polymers (IIPs) sites were created on the surface of the QDs to selectively bind $\mathrm{Cd}^{2+}$ leading to the repair of surface defects and restoration of the QD fluorescence (FL). Other common 
transition metal ions had a negligible influence on the FL of the unetched QDs. Therefore, IIPs not only retain all the virtues of MIPs, but also reduce interference by other ions due to their high specificity [62].

\subsection{Improving the sensitivity of QD-based plnanosensors}

Usually, extra clean-up and enrichment steps and potential derivatization processes are critical during laboratory analyses of trace or ultratrace contaminants, leading to more time and cost cosumption. By introducing and optimizing the appropriate PL transduction pathways, many sensitive methods based on QD-plnanosensing can effectively eliminate complex sample preparation steps and derivatization processes to ensure the reliability of the method and save time.

ELISA has received considerable attention over the past few years due to its simplicity, relatively low cost, easy operation and suitability for high-throughput analysis. However, commercially available ELISA, which is mostly based on the competitive assay format, is only suitable for qualitative analysis, since it possesses narrow sensitivity, poor reproducibility and is limited to less complex matrices. Additionally, enzyme-based labels suffer from problems of instability due to denaturation and degradation over time $[63,64]$. Conjugating organic fluorescein or rhodamine to a substitute enzyme in fluorescence-linked immunosorbent assay (FLISA) can overcome these disadvantages, whereas traditional organic fluorescent materials exhibit narrow excitations and broad, trailing emissions. Compared to organic dyes, QDs possess the dramatically better FL properties with one-third of the emission width, 20 times the brightness, and 100 times more stable against photobleaching $[16,65]$. As labels, QD-based FLISA provides substantial advantages in improving sensitivity and lowering the LOD. Utilizing CdSe/ZnS QDs to perform the FLISA array for detecting ZEN has led to a fourfold decrease in the $\mathrm{IC}_{50}$ value $(0.1 \mathrm{ng} / \mathrm{mL})$ compared to ELISA with a LOD of $0.03 \mathrm{ng} / \mathrm{mL}$, even in complex food matrices [66]. By using CdTe QDs as labels for mAb, the cFLISA method for aflatoxin $\mathrm{B}_{1}\left(\mathrm{AFB}_{1}\right)$ was developed with a LOD of $0.016 \mathrm{ng} / \mathrm{mL}$ [67]. By the use of 
multicolored (red, orange, and green) CdSe-based QDs and the immobilization of two different types of antibodies into the same well (double-analyte multiplex) or each mycotoxin antibody into separate well, two easy-to-operate QD-based FLISA techniques (single- and double-analyte multiplex) were developed to give ultra-low LODs for target mycotoxins. Real application demonstrated excellent applicability of the multiplex assays for simultaneous on-site screening of several mycotoxins in cereals [68]. CdTe QDs-coated streptavidin (QDs-SA) was also employed to improve the sensitivity of QDs-SA-cFLISA for the detection of chlorpyrifos in drinking water with a LOD of $3.8 \mathrm{ng} / \mathrm{mL}$. This technique also resulted in a 5.5 -fold increase in sensitivity and reduction in detection time of 1 hour compared to ELISA [69]. Two types of QD sensors based on icFLISA and icELISA have been integrated for simultaneously screening multiple structurally different molecules in milk. Combined with icFLISA, the hybrid immunoassay was able to simplify sample pretreatment with LOD values of $0.18 \mathrm{ng} / \mathrm{mL}$ for quinolones, $0.17 \mathrm{ng} / \mathrm{mL}$ for sulfonamides and 7.5 $\mathrm{ng} / \mathrm{mL}$ for melamine [70], which is low enough for trace determination of multipul analytes in complex matrices.

Fluorescence (Förster) resonance energy transfer (FRET)-based plnanosensors are also fairly advanced with fast liquid-phase binding kinetics, long-term stabilities, ratio metric measurements and homogeneous assays that do not require additional washing and separation steps [71]. In FRET-coated plnanosensors, selecting relational and compatible donor-acceptor pairs is essential to sustain high sensitivity. Furthermnore, QDs can serve as excellent donors or acceptors as explained by the following FRET mathematical formulas (Fig. 3A): surface multifunctionalizations dramatically increase conjunctive patterns with the acceptors, thereby shortening the distance $(r)$ between the donor-acceptor pair. The symmetric, size-tunable and narrow emissions ensure a large donor-acceptor spectral overlap integral $(J)$ and the equivalence of the FRET efficiency $(E)$. In addition, high quantum yields are essential for maximizing the Förster distance $\left(R_{0}\right)$ [72]. 
Substantial detection based on QD-assisted FRET-plnanosensors has been carried out with signal-on/off modes as shown in Table 2 and Fig. 3 (Fig. 3B, 3C). For the signal-on mode, the intrinsic sensitivity of FRET is associated with small changes in the donor-acceptor distance from effective forces, such as electrostatic interactions [73-78] and $\pi-\pi$ stacking interactions [79]. Adding analytes to disrupt the equilibrium of the FRET system will lead to PL recovery of quenching QDs due to hypercompetitive assays. Additionally, the selectivity is improved by specific interactions with antibodies [80-82], sDNA [83], aptamers [84], nicking endonucleases (NEase) [85] and DNAzymes [86]. Time-gated FRET sensors have also been studied based on the longer fluorescence lifetime of $\mathrm{Mn}^{2+}: \mathrm{CdS} / \mathrm{ZnS}$ and $\mathrm{Hg}^{2+}$-induced conformational changes in the thymine-rich oligo. This sensing system possessed ultra-sensitivity and efficiently reduced background noise with a LOD of $0.18 \mathrm{nM}$ by a time-gated mode. The system also had excellent selectivity even with interference by high concentrations of other metal ions [83]. For the signal-off mode (Fig. 3D, 3E), donor-acceptor pairs of heterogeneous donor QDs as donors, such as $\mathrm{CdSe} / \mathrm{ZnS}$ [87], $\mathrm{Mn}^{2+}: \mathrm{CdS} / \mathrm{ZnS}$ [88], CdTe [89], and commercialized QDs [90], in association with specific ligands were reported to decrease matrix effects while improving sensitivity. Recently, researchers have found the effective energy transfer occurring from QDs to analytes, which simplified the determination steps as being refrained from finding extra As and potential modifications [56]. Significant FRET is observed on benzo(a)pyrene $(\mathrm{BaP})$-loaded $\mathrm{TiO}_{2} \mathrm{NTs}$ when they are modified by CdTe QDs. This leads to a 15 fold enhancement in FL emission of $\mathrm{BaP}$ on $\mathrm{CdTe}-\mathrm{TiO}_{2}$ NTs resulting in higher sensitivity for $\mathrm{BaP}$ in the FRET based method than in direct solid and liquid FL spectroscopies [91]. These results suggest that using CdTe QDs as the acceptors and fluorescent brighteners as the donors can provide a unique FRET system which utilizes electrostatic interactions for the analysis of $\mathrm{Hg}^{2+}$ [92].

Table 2

Fig. 3 
Unlike FL, phosphorescence is a long lived process resulting from radiative recombination of the triplet excited state $T_{1}$ returning to the singlet state $S_{0}$. This can lead to superior PL properties such as long emission lifetimes, large Stokes-shifts, and minimum interference from short-lived auto-FL and scattered light. Athough phosphorescence usually occurs in low quantum yields, there have been numerous studies on the use of phosphorescence to enhance sensitivity and reliability by eliminating the interference of similar fluorescent emissions in matrices. Yan et al have developed room-temperature phosphorescence (RTP) sensing based on $\mathrm{Mn}^{2+}$ : ZnS QDs for the detection of persistent organic pollutants [93] and drug residues [94], which is unaffected by auto-FL and scattered light. The method has good sensitivity (LODs of 86 and $58.6 \mathrm{nM}$, respectively) without the need of any inducers or derivatization step. Rayleigh scattering enhancement of defect-related emission makes RTP of $\mathrm{Mn}^{2+}: \mathrm{ZnS}$ QDs well-suited for sensing 2, 4, 6-trinitrotoluene in water with a LOD of only $0.8 \mathrm{nM}$ [95]. Additionally, RTPs of $\mathrm{Fe}_{3} \mathrm{O}_{4}$ magnetic- $\mathrm{Mn}^{2+}: \mathrm{ZnS}[96,97]$, $\mathrm{Mn}^{2+}: \mathrm{ZnSe}$ [98], $\mathrm{Mn}^{2+}: \mathrm{CdTe} / \mathrm{ZnS}$ [99] QDs have been successfully introduced for sensing trace contaminants.

It is worth mentioning that some novel formats have been established based on QD PL for sensitivity enhancement of analytes at trace levels as well as avoidance of matrix effects in the environment, such as ratiometric fluorescence [100], surface enhanced raman scattering [101], and surface plasmon resonance [102]. Wang et al. [103] hybridized two differently sized CdTe QDs, which emitted red and green fluorescence, by embedding red-emitting QDs in silica nanoparticles and covalently linking QDs with the silica surface to form a dual-emissive fluorescent hybrid nanoparticle. Variations in the dual emission intensity ratios display continuous color changes from green to red, which can be clearly observed by the naked eye. This method provides significantly enhanced visual detection selectivity and sensitivity compared with single QD-based probes, and has been successfully applied in detecting residues in complex environmental samples and herbal products. 


\subsection{Simultaneously high-throughput screening of multi-contaminants}

Usually, numerous contaminants co-exist within one sample, making it necessary for detection methods to screen for multiple contaminants in a single run and be both accurate and cost-effective for displaying levels of various contaminants. Moreover, high-throughput screening of food products, medicines and environmental samples is essential for determining the characteristics of the contaminated materials and maximum residue levels, as well as the potential resistances of constituents in the same matrix. These requirements can be achieved in tandem by utilizing QDs in groups II-VI, III-V and IV-VI, and multiple size-dependent PL signals in suspended or planar arrays (Table 3).

\section{Table 3}

Flow cytometry (FCM) is a high-throughput analytical technique for most prominent suspension microarrays and can virtually discriminate between each analyte in a sample while simultaneously measuring multiple analytes based on light-scattering and fluorescence-based detection. By integrating biofunctionalized dualcolor QDs of $525 \mathrm{~nm}$ (green) and $655 \mathrm{~nm}$ (red), Yu et al. extended the capabilities of multicolor FCM for the prescreening of environmental hazards [104]. Compared to conventional analytical methods, the hyphenated technique provids significant improvements with respect to sensitivity and analysis time. This method also simplified sample manipulation on the basis of suspended bead-based competitive immunological reactions, rapid and simultaneous FCM readouts as well as high throughput, and QD-based amplification of the optical signal using a single excitation source (Fig. 4). This proposed format provides another potential platform by choosing the suitable analytes-aptamers in FCM [105].

Microfluidic technology is a new planar assay that possesses advantages of portability, minimal sample/reagent use, fast reaction times, and considerable parallel processing of samples. Zhang et al. [106] reported the combination of efficient sample handling of microfluidics with high-throughput parallel analysis of microbead based 
arrays for the detection of multiple contaminants. This microfluidic beads-based array chip obtained picomolar sensitivity. In addition, approximately 500 times the signal enhancement was obtained when adenosine sensing was performed on chip due to the enhanced mass transport capabilities inherent to microfluidics and multienzyme-linked AuNPs amplification and QD labels. Compared to conventional planar arrays, the incorporation of a microbead into a single and sealed micro-channel requires only a small amount of reagents and sample injection with minimal sample contamination.

Fig. 4

\section{Conclusions and prospectives}

Continuous concerns over hazards in association with contaminants have provide an urgent need to develop novel techniques that can quickly and accurately detect harmful contaminants in the environment, food materials, feeds, plants, medicinal herbs and other matrices. Because of their superior PL characteristics, QDs have been attained a variety of applications ranging from biological imaging, drug delivery systems design, and medical diagnoses to the detection of trace contaminants [107-115]. QD-based plnanosensors have demonstrated satisfactory performance criteria for the qualitative and quantitative analysis of various trace contaminants with enhanced selectivity and sensitivity, while also achieving simultaneous high-throughput screening of multiple contaminants and complex samples. Based on these novel QD-based plnanosensing technologies, plnanosensing platforms containing QDs can be developed for laboratory analysis, as well as on-site, fast and real-time analysis of numerous contaminants in complex matrices. However, it is important to consider the drawbacks of this method, therefore the problems and future trends relating to the development of QD-based plnanosensors for monitoring trace contaminants are discussed here.

First, how can we achieve on-site detection from laboratory analysis? In general, laboratory analysis is indispensable for detection of various contaminants. However, 
professional operation of these instruments requires greater amounts of time and higher costs. Integration of nanotechnology, microfluidics technology and gene microarrays in QD-based plnanosensorsprovides advantages of on-site, dynamic and real-time analysis, meeting the analytical demands of miniaturization and practicality with short analysis time, small costs and reagent consumption.

Another important question is how can we suppress matrix effects and improve the accuracy of on-site detection? Interference in complex matrices, particularly from components of containing similar structures to the target structure is a difficult problem in chromatographic analysis. Appropriate pretreatments on samples can be effective but are often time-consuming and lead to a loss of the targets and inaccurate results. Interferences from the matrix pose similar problems for QD-based plnanosensors. Currently, the combination of biological and chemical ligands, such as Apts, DNAzymes, MIPs and IIPs, as well as some compatible formats, such as FLISA, FRET, RTP, in QD-based plnanosensors can effectively enhance both selectivity and sensitivity and reduce or eliminate interferences. Therefore, the development of various specific receptors and compatible formats for the surface functionalization and signal amplification of QDs in the future will be important.

The final question we need to answer is how can we ensure the stability of analytical methods for simultenous detection of trace contaminants? The synthesis and surface modification of QDs may meet these stability requirements. For example, the development of quantum-sized carbon analogues, such as carbon quantum dots (CQDs, C-dots or CDs) [115-120] and graphene quantum dots (GQDs) [121-123] can build excellent probes that may be superior since CQDs and GQDs can maintain the original features of QDs but with exceptional multi-photon excitation (up-conversion) property, lower toxicity, high photostability, excellent biocompatibility, ease to be functionalized with biomolecules, and chemical inertness. As a fascinating class of "zero-dimensional" carbon nanomaterials, C-dots are spherical nanoparticles with sizes below $10 \mathrm{~nm}$ and have a great potential for widespread applications in the fields 
of biomedicine, optronics, catalysis and sensor issues. Zhou et al. [117] prepared new water-soluble fluorescent CQDs with diameters of about $3 \mathrm{~nm}$ using a facile microwave pyrolysis approach in minutes. They discovered that the CQDs could dramatically enhance the chemiluminescence intensity of potassium peroxomonosulfate-sodium sulfite-hydrochloric acid reactions. Satisfactory results were obtained through the successful application of the CQDs sensitized chemiluminescence system for the determination of aliphatic primary amines in real water samples. GQDs is a class of graphene nanomaterials with exceptional luminescence properties. Peng et al. [121] have reported a facile synthesis of GQDs on a large scale with acidic exfoliation and etching of pitch carbon fibers, which were rich in distributed graphitic domains in their original frameworks. We believe that additional studies on quantum-sized carbon analogues will be the next big small things and get more exciting applications in other areas, such as energy storage and conversion, photocatalysis, and display technologies.

In conclusion, QDs are promising nanoparticles that show excellent potential for various applications in the fields of high-throughput determination of various trace contaminants.

\section{Acknowledgements}

The authors are grateful for the support from the National Science Foundation of China $(81274072,81473346)$ and Xiehe New Star project.

\section{References}

[1] W.J. Kong, T.T. Xie, J.Y. Li, J.H. Wei, F. Qiu, A.D. Qi, Y.G. Zheng, M.H. Yang, Analysis of fumonisins B1 and B2 in spices and aromatic and medicinal herbs by HPLC-FLD with on-line post-column derivatization and positive confirmation by LC-MS/MS, Analyst 137 (2012) 3166-3174.

[2] T. Portolés, L. Cherta, J. Beltran, F. Hernández, Improved gas chromatography-tandem mass spectrometry determination of pesticide 
residues making use of atmospheric pressure chemical ionization, J. Chromatogr. A 1260 (2012) 183-192.

[3] F.Y. Yu, M.M. Vdovenko, J.J. Wang, I.Y. Sakharov, Comparison of enzyme-linked immunosorbent assays with chemiluminescent and colorimetric detection for the determination of ochratoxin A in food, J. Agric. Food Chem. 59 (2011) 809-813.

[4] P.O. Otieno, P.O. Owuor, J.O. Lalah, G. Pfister, K.W. Schramm, Comparative evaluation of ELISA kit and HPLC-DAD for the determination of chlorpyrifos ethyl residues in water and sediments. Talanta 117 (2013) 250-257.

[5] W.J. Kong, S.Y. Liu, F. Qiu, X.H. Xiao, M.H. Yang, Simultaneous multi-mycotoxin determination in nutmeg by ultrasound-assisted solid-liquid extraction and immunoaffinity column clean-up coupled with liquid chromatography and on-line post-column photochemical derivatization fluorescence detection, Analyst 138 (2013) 2729-2739.

[6] J.H. Kim, S.Y. Lim, D.H. Nam, J. Ryu, S.H. Ku, C.B.Park, Self-assembled, photoluminescent peptide hydrogel as a versatile platform for enzyme-based optical biosensors, Biosens. Bioelectron. 26 (2011) 1860-1865.

[7] O. Adegoke, P.B.C. Forbes, Challenges and advances in quantum dot fluorescent probes to detect reactive oxygen and nitrogen species: A review, Anal. Chim. Acta 862 (2015) 1-13.

[8] C.A. Kerr, R. de la Rica, Photoluminescent nanosensors for intracellular detection, Anal. Methods DOI: 10.1039/C5AY00489F.

[9] J.M. Costa-Fernández, R. Pereiro, A. Sanz-Medel, The use of luminescent quantum dots for optical sensing, Trends Anal. Chem. 25 (2006) 207-218.

[10] M.F. Frasco, N. Chaniotakis, Bioconjugated quantum dots as fluorescent probes for bioanalytical applications, Anal. Bioanal. Chem. 396 (2010) 
$229-240$.

[11] F.A. Esteve-Turrillas, A. Abad-Fuentes, Applications of quantum dots as probes inimmunosensing of small-sized analytes, Biosens. Bioelectron. 41 (2013) 12-29.

[12] C. Frigerio, D.S.M. Ribeiro, S.S.M. Rodrigues, V.L.R.G. Abreu, J.A.C. Barbosa, J.A.V. Prior, K.L. Marques, J.L.M. Santos, Application of quantum dots as analytical tools in automated chemical analysis: A review, Anal. Chim. Acta 735 (2012) 9-22.

[13] H. Chen, L. Lin, Z. Lin, G.S. Guo, J.M. Lin, Chemiluminescence arising from the decomposition of peroxymonocarbonate and enhanced by CdTe quantum dots, J. Phys. Chem. A 114 (2010) 10049-10058.

[14] I. Costas-Mora, V. Romero, I. Lavilla, C. Bendicho, An overview of recent advances in the application of quantum dots as luminescent probes to inorganic-trace analysis, TrAC, Trends Anal. Chem. 57 (2014) 64-72.

[15] H. Zhou, J. Liu, S.S. Zhang, Quantum dot-based photoelectric conversion for biosensing applications, TrAC. Trends Anal. Chem. 67 (2015) 56-73.

[16] H. Chen, L. Lin, H.F. Li, J.M. Lin, Quantum dots-enhanced chemiluminescence: Mechanism and application, Coordin. Chem. Rev. 263-264 (2014) 86-100.

[17] L. Cui, X.P. He, G.R. Chen, Recent progress in quantum dot based sensors, RSC Adv. 5 (2015) 26644-26653.

[18] European Commission, Commission Regulation (EC) 1881/2006: setting maximum level for certain contaminants in foodstuff. Off. J. Eur. Union, 2012, L364, 5-24.

[19] T.B. Whitaker, M.W. Trucksess, C.M. Weaver, A. Slate, Sampling and analytical variability associated with the determination of aflatoxins and ochratoxin A in bulk lots of powdered ginger marketed in 1-lb bags, Anal. Bioanal. Chem. 395 (2009) 1291-1299. 
[20] M.W. Trucksess, T.B. Whitaker, C.M. Weaver, A. Slate, F.G. Giesbrecht, J.I. Rader, J.M. Betz, Sampling and analytical variability associated with the determination of total aflatoxins and ochratoxin A in powdered ginger sold as a dietary supplement in capsules, J. Agric. Food Chem. 57 (2009) 321-325.

[21] H.Y. Niu, S.H. Wang, T. Zeng, Y.X. Wang, X.L. Zhang, Z.F. Meng, Y.Q. Cai, Preparation and characterization of layer-by-layer assembly of thiols/Ag nanoparticles/polydopamine on PET bottles for the enrichment of organic pollutants from water samples, J. Mater. Chem. 22 (2012) 15644-15653.

[22] S. Polati, M. Bottaro, P. Frascarolo, F. Gosetti, V. Gianotti, M.C. Gennaro, HPLC-UV and HPLC-MSn multiresidue determination of amidosulfuron, azimsulfuron, nicosulfuron, rimsulfuron, thifensulfuron methyl, tribenuron methyl and azoxystrobin in surface waters, Anal. Chim. Acta 579 (2006) 146-151.

[23] S.K. Kim, H. Chang, E.T. Zellers, Microfabricated gas chromatograph for the selective determination of trichloroethylene vapor at sub-parts-per-billion concentrations in complex mixtures, Anal. Chem. 83 (2011) 7198-7206.

[24] P.D. Andrade, J.L.G. da Silva, E.D. Caldas, Simultaneous analysis of aflatoxins B1, B2, G1, G2, M1 and ochratoxinA in breast milk by high-performance liquidchromatography/fluorescence after liquid-liquid extraction with low temperature purification (LLE-LTP), J. Chromatogr. A 1304 (2013) 61-68.

[25] B.V. Dorst, J. Mehta, K. Bekaert, E. Rouah-Martin, W. De Coen, P. Dubruel, R. Blust, J. Robbens. Recent advances in recognition elements of food and environmental biosensors: A review, Biosens. Bioelectron. 26 (2010) 1178-1194. 
[26] M.F. Frasco, N. Chaniotakis, Semiconductor quantum dots in chemical sensors and biosensors, Sensors 9 (2009) 7266-7286.

[27] A. Amine, H. Mohammadi, I. Bourais, G. Palleschi, Enzyme inhibition-based biosensors for food safety and environmental monitoring, Biosens. Bioelectron. 21 (2006) 1405-1423.

[28] Z.Z. Zheng, Y.L. Zhou, X.Y. Li, S.Q. Liu, Z.Y. Tang, Highly-sensitive organophosphorous pesticide biosensors based on nanostructured films of acetylcholinesterase and CdTe quantum dots, Biosens. Bioelectron. 26 (2011) 3081-3085.

[29] T.K.C. Tran, D.C. Vu, T.D.T. Ung, H.Y. Nguyen, N.H. Nguyen, T.C. Dao, T.N. Pham, Q.L. Nguyen, Fabrication of fluorescence-based biosensors from functionalized $\mathrm{CdSe}$ and $\mathrm{CdTe}$ quantum dots for pesticide detection, Adv. Nat. Sci.: Nanosci. Nanotechnol. 3 (2012) 35008-35012.

[30] Z.Z. Zheng, X.Y. Li, Z.F. Dai, S.Q. Liu, Z.Y. Tang, Detection of mixed organophosphorus pesticides in real samples using quantum dots/bi-enzyme assembly multilayers, J. Mater. Chem. 21 (2011) 16955-16962.

[31] X.W. Meng, J.F. Wei, X.L. Ren, J. Ren, F.Q. Tang, A simple and sensitive fluorescence biosensor for detection of organophosphorus pesticides using H2O2-sensitive quantum dots/bi-enzyme, Biosens. Bioelectron. 47 (2013) 402-407.

[32] C.X. Guo, J.L. Wang, J. Cheng, Z.F. Dai, Determination of trace copper ions with ultrahigh sensitivity and selectivity utilizing CdTe quantum dots coupled with enzyme inhibition, Biosens. Bioelectron. 36 (2012) 69-74.

[33] J.P. Yuan, W.W. Guo, E.K. Wang, Utilizing a CdTe quantum dots-enzyme hybrid system for the determination of both phenolic compounds and hydrogen peroxide, Anal. Chem. 80 (2008) 1141-1145.

[34] X.J. Ji, J.Y. Zheng, J.M. Xu, V.K. Rastogi, T.C. Cheng, J.J. DeFrank, R.M. 
Leblanc, (CdSe)ZnS quantum dots and organophosphorus hydrolase bioconjugate as biosensors for detection of paraoxon, J. Phys. Chem. B 109 (2005) 3793-3799.

[35] S.A. Park, E. Jang, W.G. Koh, B. Kim, Fabrication and characterization of optical biosensors using polymer hydrogel microparticles and enzyme-quantum dot conjugates, Sens. Actuat. B-Chem. 150 (2010) $120-125$.

[36] S.A. Park, E. Jang, W.G. Koh, B. Kim, Development of analytic microdevices for the detection of phenol using polymer hydrogel particles containing enzyme-QD conjugates, Talanta 84 (2011) 1000-1003.

[37] E. Jang, K.J. Son, B. Kim, W.G. Koh, Phenol biosensor based on hydrogel microarrays entrapping tyrosinase and quantum dots, Analyst 135 (2010) 2871-2878.

[38] J.P. Yuan, N. Gaponik, A. Eychmüller, Application of polymer quantum dot-enzyme hybrids in the biosensor development and test paper fabrication, Anal. Chem. 84 (2012) 5047-5052.

[39] Q. Zhang, Y.Y. Qu, M. Liu, X.L. Li, J.T. Zhou, X.W. Zhang, H. Zhou, A sensitive enzyme biosensor for catecholics detection via the inner filter effect on fluorescence of CdTe quantum dots, Sens. Actuat. B-Chem. 173 (2012) 477-482.

[40] H.Y. Zhu, U. Sikora, A. Ozcan, Quantum dot enabled detection of Escherichia coli using a cell-phone, Analyst 137 (2012) 2541-2544.

[41] L.J. Yang, Y.B. Li, Quantum dots as fluorescent labels for quantitative detection of Salmonella typhimurium in chicken carcass wash water, J. Food Prot. 68 (2005) 1241-1245.

[42] Y. Zhao, M.Q. Ye, Q.G. Chao, N.Q. Jia, Y. Ge, H.B. Shen, Simultaneous detection of multifood-borne pathogenic bacteria based on functionalized quantum dots coupled with immunomagnetic separation in food samples, J. 
Agric. Food Chem. 57 (2009) 517-524.

[43] S. Tang, P. Tong, H. Li, J. Tang, L.L. Zhang, Ultrasensitive electrochemical detection of $\mathrm{Pb} 2+$ based on rolling circle amplification and quantum dots tagging, Biosens. Bioelectron. 42 (2013) 608-611.

[44] P. Tong, W.W. Zhao, L. Zhang, J.J. Xu, H.Y. Chen, Double-probe signal enhancing strategy for toxin aptasensing based on rolling circle amplification, Biosens. Bioelectron. 33 (2012) 146-151.

[45] L.H. Liu, X.H. Zhou, H.C. Shi, Portable optical aptasensor for rapid detection of mycotoxin with a reversible ligand-grafted biosensing surface, Biosens. Bioelectron. 72 (2015) 300-305.

[46] R. Freeman, X. Liu, I. Willner, Chemiluminescent and chemiluminescence resonance energy transfer (CRET) detection of DNA, metal ions, and aptamer-substrate complexes using hemin/G-quadruplexes and $\mathrm{CdSe} / \mathrm{ZnS}$ quantum dots, J. Am. Chem. Soc. 133 (2011) 11597-11604.

[47] R. Freeman, T. Finder, I. Willner, Multiplexed analysis of $\mathrm{Hg} 2+$ and $\mathrm{Ag}+$ ions by nucleic acid functionalized $\mathrm{CdSe} / \mathrm{ZnS}$ quantum dots and their use for logic gate operations, Angew. Chem. Int. Ed. 48 (2009) 7818-7821.

[48] L.B. Wang, W. Chen, W.W. Ma, L.Q. Liu, W. Ma, Y. Zhao, Y.Y. Zhu, L.Q. Xu, H. Kuang, C.L. Xu, Fluorescent strip sensor for rapid determination of toxins, Chem. Commun. 47 (2011) 1574-1576.

[49] M.J. Ruedas-Rama, E.A.H. Hall, Azamacrocycle activated quantum dot for zinc ion detection, Anal. Chem. 80 (2008) 8260-8268.

[50] F.G. Qu, H. Li, Selective molecular recognition of polycyclic aromatic hydrocarbons using CdTe quantum dots with cyclodextrin as supramolecular nano-sensitizers in water, Sens. Actuat. B-Chem. 135 (2009) 499-505.

[51] H.B. Li, Y. Zhang, X.Q. Wang, D.J. Xiong, Y.Q. Bai, Calixarene capped quantum dots as luminescent probes for $\mathrm{Hg} 2+$ ions, Mater. Lett. 61 (2007) 
1474-1477.

[52] T. Li, Y.Y. Zhou, J.Y. Sun, D.B. Tang, S.X. Guo, X.P. Ding, Ultrasensitive detection of mercury(II) ion using CdTe quantum dots in sol-gel-derived silica spheres coated with calixarene as fluorescent probes, Microchim. Acta 175 (2011) 113-119.

[53] F.G. Qu, X.F. Zhou, J. Xu, H.B. Li, G.Y. Xie, Luminescence switching of CdTe quantum dots in presence of p-sulfonato calixarene to detect pesticides in aqueous solution, Talanta 78 (2009) 1359-1363.

[54] C.P. Han, H.B. Li, Host-molecule-coated quantum dots as fluorescent sensors, Anal. Bioanal. Chem. 397 (2010) 1437-1444.

[55] Y.P. Chen, D.N. Wang, Y.M. Yin, L.Y. Wang, X.F. Wang, M.X. Xie, Quantum dots capped with dummy molecularly imprinted film as luminescent sensor for the determination of tetrabromobisphenol $\mathrm{A}$ in water and soils, J. Agric. Food Chem. 60 (2012) 10472-10479.

[56] Y.Y. Zhao, Y.X. Ma, H. Li, L.Y. Wang, Composite QDs@ MIP nanospheres for specific recognition and direct fluorescent quantification of pesticides in aqueous media, Anal. Chem. 84 (2012) 386-395.

[57] GZ. Fang, C. Fan, H.L. Liu, M.F. Pan, H.D. Zhu, S. Wang, A novel molecularly imprinted polymer on $\mathrm{CdSe} / \mathrm{ZnS}$ quantum dots for highly selective optosensing of mycotoxin zearalenone in cereal samples. RSC Adv. 4 (2014) 2764-2771.

[58] X.H. Ren, H.C. Liu, L.G. Chen, Fluorescent detection of chlorpyrifos using $\mathrm{Mn}(\mathrm{II})$-doped $\mathrm{ZnS}$ quantum dots coated with a molecularly imprinted polymer, Microchim. Acta, 182 (2014) 193-200.

[59] X.H. Ren, L.G. Chen, Quantum dots coated with molecularly imprinted polymer as fluorescence probe for detection of cyphenothrin. Biosens. Bioelectron. 64 (2015) 182-188.

[60] J.X. Liu, H. Chen, Z. Lin, J.M. Lin, Preparation of surface imprinting 
polymer capped Mn-doped ZnS quantum dots and their application for chemiluminescence detection of 4-nitrophenol in tap water, Anal. Chem. $82(2010) 7380-386$.

[61] M. Yang, A.J. Han, J.L. Duan, Z.P. Li, Y.C. Lai, J.H. Zhan, Magnetic nanoparticles and quantum dots co-loaded imprinted matrix for pentachlorophenol, J. Hazard. Mater. 237-238 (2012) 63-70.

[62] P. Wu, X.P. Yan, A simple chemical etching strategy to generate "ion-imprinted" sites on the surface of quantum dots for selective fluorescence turn-on detecting of metal ions, Chem. Commun. 46 (2010) 7046-7048.

[63] N.W. Turner, S. Subrahmanyam, S.A. Piletsky, Analytical methods for determination of mycotoxins: A review, Anal. Chim. Acta 632 (2009) $168-180$.

[64] X. Feng, W.J. Kong, M.H. Yang, Z. Ouyang, Latest advancement for detection methods of mycotoxins in traditional Chinese medicine, World Sci. Technol. Mod. Tradit. Chin. Med. Mater. Med. 14 (2012) 1944-1952.

[65] H. Kuang, Y. Zhao, W. Ma, L.G.Xu, L.B. Wang, C.L. Xu, Recent developments in analytical applications of quantum dots, TrAC. Trends Anal. Chem. 30 (2011) 1620-1636.

[66] N.V. Beloglazova, E.S. Speranskaya, S. De Saeger, Z. Hens, S. Abé, I.Y. Goryacheva, Quantum dot based rapid tests for zearalenone detection, Anal. Bioanal. Chem. 403 (2012) 3013-3024.

[67] Z.W. Zhang, Y.Y. Li, P. Li, Q. Zhang, W. Zhang, X.F. Hu, X.X. Ding, Monoclonal antibody-quantum dots CdTe conjugate-based fluoroimmunoassay for the determination of aflatoxin B1 in peanuts, Food Chem. 146 (2014) 314-319.

[68] N.V. Beloglazova, E.S. Speranskaya, A. Wu, Z. Wang, M. Sanders, V.V. Goftman, D. Zhang, I. Y. Goryacheva, S. De Saeger, Novel multiplex 
fluorescent immunoassays based on quantum dot nanolabels for mycotoxins determination, Biosens. Bioelectron. 62 (2014) 59-65.

[69] Y.P. Chen, H.L. Ren, N. Liu, N. Sai, X.Y. Liu, Z. Liu, Z.X. Gao, B.A. Ning, A fluoroimmunoassay based on quantum dot-streptavidin conjugate for the detection of chlorpyrifos, J. Agric. Food Chem. 58 (2010) $8895-8903$.

[70] K. Zhu, J.C. Li, Z.H. Wang, H.Y. Jiang, R.C. Beier, F. Xu, J.Z. Shen, S.Y. Ding, Simultaneous detection of multiple chemical residues in milk using broad-specificity antibodies in a hybrid immunosorbent assay, Biosens. Bioelectron. 26 (2011) 2716-2719.

[71] M. Stanisavljevic, S. Krizkova, M. Vaculovicova, R. Kizek, V. Adam, Quantum dots-fluorescence resonance energy transfer-based nanosensors and their application, Biosens. Bioelectron. DOI: http://dx.doi.org/10.1016/j.bios.2015.06.076.

[72] W.R. Algar, A.J. Tavares, U.J. Krull, Beyond labels: A review of the application of quantum dots as integrated components of assays, bioprobes, and biosensors utilizing optical transduction, Anal. Chim. Acta 673 ( 2010) $1-25$.

[73] Y.S. Xia, L. Song, C.Q. Zhu, Turn-on and near-infrared fluorescent sensing for 2,4,6-trinitrotoluene based on hybrid (gold nanorod)-(quantum dots) assembly, Anal. Chem. 83 (2011) 1401-1407.

[74] R.J. Gui, X.Q. An, W.X. Huang, An improved method for ratiometric fluorescence detection of $\mathrm{pH}$ and $\mathrm{Cd} 2+$ using fluorescein isothiocyanate-quantum dots conjugates, Anal. Chim. Acta 767 (2013) 134-140.

[75] P. Yang, Y. Zhao, Y. Lu, Q. Z.Xu, X.W. Xu, L. Dong, S.H. Yu, Phenol formaldehyde resin nanoparticles loaded with CdTe quantum dots: a fluorescence resonance energy transfer probe for optical visual detection of 
copper(II) ions, ACS Nano 5 (2011) 2147-2154.

[76] J.J. Guo, Y. Zhang, Y.L. Luo, F. Shen, C.Y. Sun, Efficient fluorescence resonance energy transfer between oppositely charged CdTe quantum dots and gold nanoparticles for turn-on fluorescence detection of glyphosate, Talanta 125 (2014) 385-392.

[77] M. Xue, X. Wang, L.L. Duan, W. Gao, L.F. Ji, B. Tang, A new nanoprobe based on FRET between functional quantum dots and gold nanoparticles for fluoride anion and its applications for biological imaging, Biosens. Bioelectron. 36 (2012) 168-173.

[78] Q. Zhao, X.L. Rong, H.B. Ma, G.H. Tao, Dithizone functionalized $\mathrm{CdSe} / \mathrm{CdS}$ quantum dots as turn-on fluorescent probe for ultrasensitive detection of lead ion, J. Hazard. Mater. 250 (2013) 45-52.

[79] M. Li, X.J. Zhou, S.W. Guo, N.Q. Wu, Detection of lead (II) with a "turn-on" fluorescent biosensor based on energy transfer from $\mathrm{CdSe} / \mathrm{ZnS}$ quantum dots to graphene oxide, Biosens. Bioelectron. 43 (2013) 69-74.

[80] W. Xu, Y.H. Xiong, W.H. Lai, Y. Xu, C.M. Li, M.Y. Xie, A homogeneous immunosensor for AFB1 detection based on FRET between different-sized quantum dots, Biosens. Bioelectron. 56 (2014) 144-150.

[81] R. Zekavati, S. Safi, S.J. Hashemi, T. Rahmani-Cherati, M. Tabatabaei, A. Mohsenifar, M. Bayat, Highly sensitive FRET-based fluorescence immunoassay for aflatoxin B1 using cadmium telluride quantum dots, Microchim. Acta 180 (2013) 1217-1223.

[82] D. Bu, H.S. Zhuang, G.X. Yang, X.X. Ping, An immunosensor designed for polybrominated biphenyl detection based on fluorescence resonance energy transfer (FRET) between carbon dots and gold nanoparticles, Sens. Actuat. B-Chem. 195 (2014) 540-548.

[83] D.W. Huang, C.G. Niu, X.Y. Wang, X.X. Lv, G.M. Zeng, "Turn-on" fluorescent sensor for $\mathrm{Hg} 2+$ based on single-stranded DNA functionalized 
$\mathrm{Mn}: \mathrm{CdS} / \mathrm{ZnS}$ quantum dots and gold nanoparticles by time-gated mode, Anal. Chem. 85 (2013), 1164-1170.

[84] C.Y. Zhang, L.W. Johnson, Single quantum-dot-based aptameric nanosensor for cocaine, Anal. Chem. 81 (2009) 3051-3055.

[85] J. Ma, Y.H. Chen, Z. Hou, W. Jiang, L. Wang, Selective and sensitive mercuric (ii) ion detection based on quantum dots and nicking endonuclease assisted signal amplification, Biosens. Bioelectron. 43 (2013) 84-87.

[86] C.S. Wu, M.K. Khaing Oo, X.D. Fan, Highly sensitive multiplexed heavy metal detection using quantum-dot-labeled DNAzymes, ACS Nano 4 (2010) 5897-5904.

[87] M. Li, Q.Y. Wang, X.D. Shi, L.A. Hornak, N.Q. Wu, Detection of mercury(II) by quantum dot/DNA/gold nanoparticle ensemble based nanosensor via nanometal surface energy transfer, Anal. Chem. 83 (2011) 7061-7065.

[88] D.W. Huang, C.G. Niu, M. Ruan, X.Y. Wang, G.M. Zeng, C.H. Deng, Highly sensitive strategy for $\mathrm{Hg} 2+$ detection in environmental water samples using long lifetime fluorescence quantum dots and gold nanoparticles, Environ. Sci. Technol. 47 (2013) 4392-4398.

[89] C.L. Hao, L.G. Xua, C.R. Xing, H. Kuang, L.B. Wang, C.L. Xu, Oligonucleotide-based fluorogenic sensor for simultaneous detection of heavy metal ions, Biosens. Bioelectron. 36 (2012) 174-178.

[90] F. Long, C.M. Gu, A.Z. Gu, H.C. Shi, Quantum dot/carrier-protein/haptens conjugate as a detection nanobioprobe for FRET-based immunoassay of small analytes with all-fiber microfluidic biosensing platform, Anal. Chem. 84 (2012) 3646-3653.

[91] L.X. Yang, B.B. Chen, S.L. Luo, J. X.Li, R.H. Li, Q.Y. Cai, Sensitive detection of polycyclic aromatic hydrocarbons using CdTe quantum 
dot-modified $\mathrm{TiO} 2$ nanotube array through fluorescence resonance energy transfer, Environ. Sci. Technol. 44 (2010) 7884-7889.

[92] H.L. Tao, X.F. Liao, M.Z. Xu, S.H. Li, F.X. Zhong, Z. S.Yi, Determination of trace $\mathrm{Hg} 2+$ ions based on the fluorescence resonance energy transfer between fluorescent brightener and CdTe quantum dots, J. Lumin. 146 (2014) 376-381.

[93] H.F. Wang, Y. He, T.R. Ji, X.P.Yan, Surface molecular imprinting on Mn-doped ZnS quantum dots for room-temperature phosphorescence optosensing of pentachlorophenol in water, Anal. Chem. 81 (2009) $1615-1621$.

[94] P. Wu, Y. He, H.F. Wang, X.P. Yan, Conjugation of glucose oxidase onto Mn-doped $\mathrm{ZnS}$ quantum dots for phosphorescent sensing of glucose in biological fluids, Anal. Chem. 82 (2010) 1427-1433.

[95] W.S. Zou, D. Sheng, X.Ge, J.Q. Qiao, H.Z. Lian, Room-temperature phosphorescence chemosensor and Rayleigh scattering chemodosimeter dual-recognition probe for 2,4,6-trinitrotoluene based on manganese-doped ZnS quantum dots, Anal. Chem. 83 (2011) 30-37.

[96] W.S. Zou, J.Y. Yang, T.T. Yang, X. Hu, H.Z. Lian, Magnetic-room temperature phosphorescent multifunctional nanocomposites as chemosensor for detection and photo-driven enzyme mimetics for degradation of 2,4,6-trinitrotoluene, J. Mater. Chem. 22 (2012) 4720-4727.

[97] H.F. Wang, Y.Y. Wu, X.P. Yan, Room-temperature phosphorescent discrimination of catechol from resorcinol and hydroquinone based on sodium tripolyphosphate capped Mn-doped $\mathrm{ZnS}$ quantum dots, Anal. Chem. 85 (2013) 1920-1925.

[98] D. Zhu, Y. Chen, L.P. Jiang, J. Geng, J.R. Zhang, J.J. Zhu, Manganese-doped $\mathrm{ZnSe}$ quantum dots as a probe for time-resolved fluorescence detection of 5-fluorouracil, Anal. Chem. 83 (2011) 
9076-9081.

[99] S.Y. Lü, T. Ye, X. Jiang, J.J. Wang, G.F. Wei, J.Q. Lü, Study on synthesis of Mn-doped CdTe/ZnS quantum dots and phosphorescence quenching method for the detection of ultra trace mercury ions in water, Acta Chim. Sinica 69 (2011) 831-837.

[100] K. Zhang, H.B. Zhou, Q.S. Mei, S.H. Wang, G.J. Guan, R.Y. Liu, J. Zhang, Z.P. Zhang, Instant visual detection of trinitrotoluene particulates on various surfaces by ratiometric fluorescence of dual-emission quantum dots hybrid, J. Am. Chem. Soc. 133 (2011) 8424-8427.

[101] C. Carrillo-Carrión, B.M. Simonet, M. Valcárcel, B. Lendl, Determination of pesticides by capillary chromatography and SERS detection using a novel Silver-Quantum dots "sponge" nanocomposite, J. Chromatogr. A 1225 (2012) 55-61.

[102] G.P. Anderson, R.H. Glaven, W.R. Algar, K. Susumu, M.H. Stewart, I.L. Medintz, E.R. Goldman, Single domain antibody-quantum dot conjugates for ricin detectionby both fluoroimmunoassay and surface plasmon resonance, Anal. Chim. Acta 786 (2013) 132-138.

[103] J.L. Yao, K. Zhang, H.J. Zhu, F. Ma, M.T. Sun, H. Yu, J. Sun, S.H. Wang, Efficient ratiometric fluorescence probe based on dual-emission quantum dots hybrid for on-site determination of copper ions, Anal. Chem. 85 (2013) 6461-6468.

[104] H.W. Yu, I.S. Kim, R. Niessner, D. Knopp, Multiplex competitive microbead-based flow cytometric immunoassay using quantum dot fluorescent labels, Anal. Chim. Acta 750 (2012) 191-198.

[105] N. Duan, S.J. Wu, Y. Yu, X.Y. Ma, Y. Xia, X.J. Chen, Y.K. Huang, Z.P. Wang, A dual-color flow cytometry protocol for the simultaneous detection of Vibrio parahaemolyticus and Salmonella typhimurium using aptamer conjugated quantum dots as labels, Anal. Chim. Acta 804 (2013) 
$151-158$.

[106] H. Zhang, X.J. Hu, X. Fu, Aptamer-based microfluidic beads array sensor for simultaneous detection of multiple analytes employing multienzymelinked nanoparticle amplification and quantum dots labels, Biosen. Bioelectron. 57 (2014) 22-29.

[107] C.F. Peng, Z.K Li, Y.Y. Zhu, W. Chen, Y. Yuan, L.Q. Liu, Q.S. Li, D.H. Xu, R.R. Qiao, L.B. Wang, S.F. Zhu, Z.Y. Jin, C.L. Xu, Simultaneous and sensitive determination of multiplex chemical residues based on multicolor quantum dot probes, Biosens. Bioelectron. 24 (2009) 3657-3662.

[108] H.L. Meng, G.H. Chen, X, Guo, P, Chen, Q.H. Cai, Y.F. Tian, Determination of five quinolone antibiotic residues in foods by micellar electrokinetic capillary chromatography with quantum dot indirect laser-induced fluorescence, Anal. Bioanal. Chem. 406 (2014) 3201-3208.

[109] G.H. Chen, J. Sun, Y.J. Dai, M. Dong, Determination of nicotinyl pesticide residues in vegetables by micellar electrokinetic capillary chromatography with quantum dot indirect laser-induced fluorescence, Electrophoresis 33 (2012) 2192-2196.

[110] Z.B. Shang, Y. Wang, W.J. Jin, Triethanolamine-capped CdSe quantum dots as fluorescent sensors for reciprocal recognition of mercury (II) and iodide in aqueous solution, Talanta 78 (2009) 364-369.

[111] H. Xu, R. Miao, Z. Fang, X.H. Zhong, Quantum dot-based "turn-on" fluorescent probe for detection of zinc and cadmium ions in aqueous media, Anal. Chim. Acta 687 (2011) 82-88.

[112] Q. Ma, E.N. Ha, F.P. Yang, X.G. Su, Synchronous determination of mercury (II) and copper (II) based on quantum dots-multilayer film, Anal. Chim. Acta 701 (2011) 60-65.

[113] M. Algarra, B.B. Campos, B. Alonso, M.S. Miranda, Á.M. Martínez, C.M. Casado, J.C.G. Esteves da Silva, Thiolated DAB dendrimers and CdSe 
quantum dots nanocomposites for $\mathrm{Cd}$ (II) or $\mathrm{Pb}$ (II) sensing, Talanta 88 (2012) 403-407.

[114] Y.H. Yi, G.B. Zhu, C. Liu, Y.Huang, Y.Y. Zhang, H.T. Li, J.N. Zhao, S.Z. Yao, A label-free silicon quantum dots-based photoluminescence sensor for ultrasensitive detection of pesticides, Anal. Chem. 85 (2013) 11464-11470.

[115] J.C.G. Esteves da Silva, H.M.R. Gonçalves, Analytical and bioanalytical applications of carbon dots, TrAC Trends Anal. Chem. 30 (2011) $1327-1336$.

[116] Z. Lin, W. Xue, H. Chen, J.M. Lin, Peroxynitrous-acid-induced chemiluminescence of fluorescent carbon dots for nitrite sensing, Anal. Chem. 83 (2011) 8245-8251.

[117] Y. Zhou, G.W. Xing, H. Chen, N. Ogawa, J.M. Lin, Carbon nanodots sensitized chemiluminescence on peroxomonosulfate-sulfite-hydrochloric acid system and its analytical applications, Talanta 99 (2012) 471-477.

[118] Y.F. Wang, A.G. Hu, Carbon quantum dots: synthesis, properties and applications, J. Mater. Chem. C 2 (2014) 6921-6939.

[119] W.J. Liu, J. Yao, H. Chai, Z.B. Zhao, C. Zhang, J.N. Jin, M.M.F. Choic, Concentration-dependent effect of photoluminescent carbon dots on the microbial activity of the soil studied by combination methods, Environ. Toxicol. Pharmacol. 39 (2015) 857-863.

[120] Z. Lin, X.N. Dou, H.F. Li, Y. Ma, J.M. Lin, Nitrite sensing based on the carbon dots-enhanced chemiluminescence from peroxynitrous acid and carbonate, Talanta 132 (2015) 457-462.

[121] J. Peng, W. Gao, B.K. Gupta, Z. Liu, R. Romero-Aburto, L.H. Ge, L. Song, L.B. Alemany, X.B. Zhan, G.H. Gao, S.A. Vithayathil, B.A. Kaipparettu, A.A. Marti, T. Hayashi, J.J. Zhu, P.M. Ajayan, Graphene quantum dots derived from carbon fibers, Nano Lett. 12 (2012) 844-849. 
[122] C.K. Chua, Z. Sofer, P. Šimek, O. Jankovský, K. Klímová, S. Bakardjieva, Š.H. Kučková, M. Pumera, Synthesis of strongly fluorescent graphene quantum dots by cage-opening buckminsterfullerene, ACS Nano, 9 (2015) 2548-2555.

[123] X.T. Zheng, A. Ananthanarayanan, K.Q. Luo, P. Chen, Glowing graphene quantum dots and carbon dots: Properties, syntheses, and biological applications, Small, 11 (2015) 1620-1636. 


\section{Figure lengends}

Figure 1. Requirements and solutions of QD-based sensors for high-throughput determination of trace contaminants.

Figure 2. Strategy of enzyme-based QD plnanosensors for high-throughput determination of trace contaminants.

(A: Enzymes inhibition [28-32]; B: Enzymes catalytic oxidation [34-39])

Figure 3. Schematics and strategy of QD-based fluorescence resonance energy transfer (FRET) plnanosensors for high-throughput determination of trace contaminants.

(A: FRET mathematical formulas; B, C: Signal-on mode [73-79, 85, 86]; D, E: Signal-off mode [56, 87-91])

Figure 4. Multiplex competitive microbead-based flow cytometry (FCM) using dualcolor QD labels [104]. 
Figures

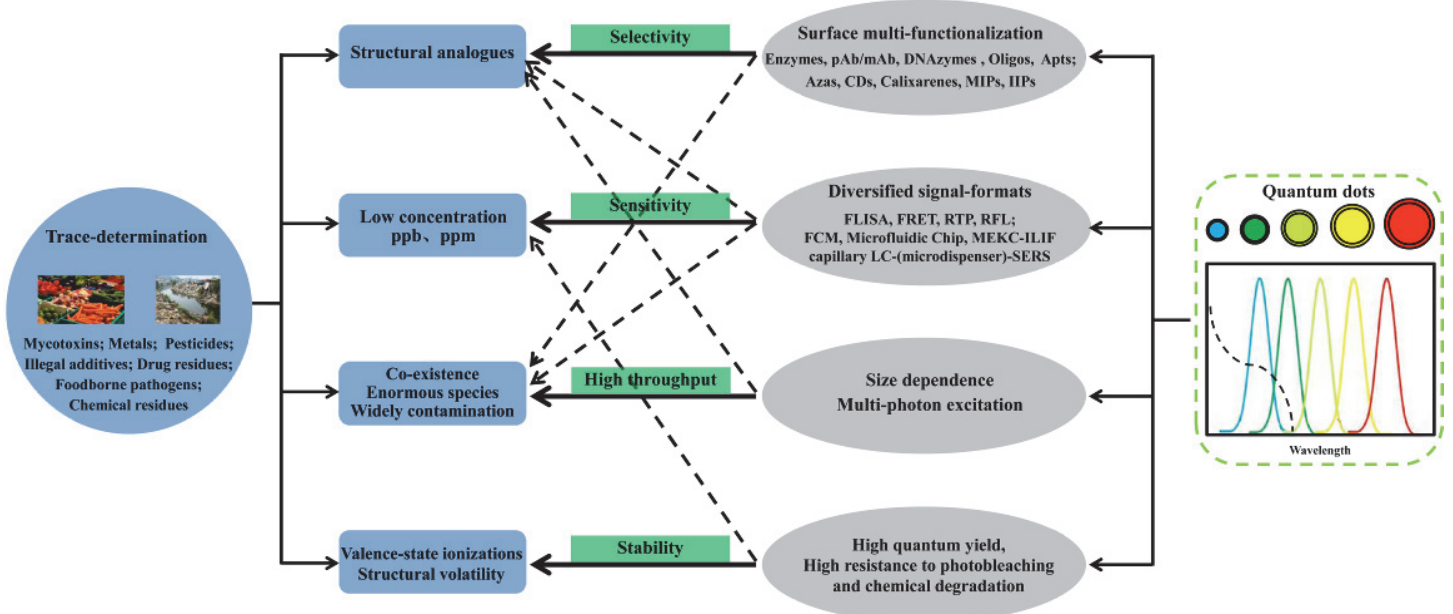

Figure 1 


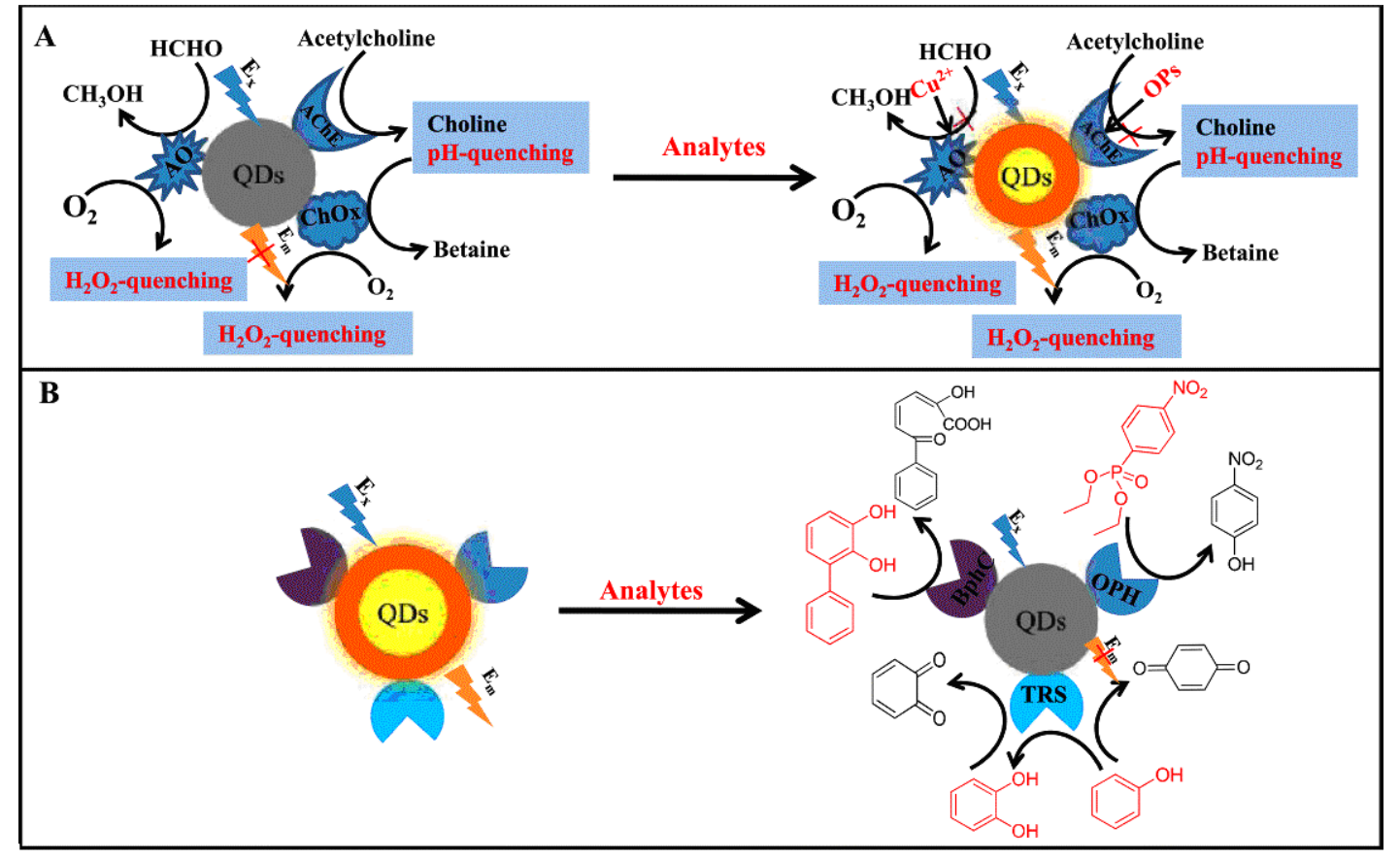

Figure 2 


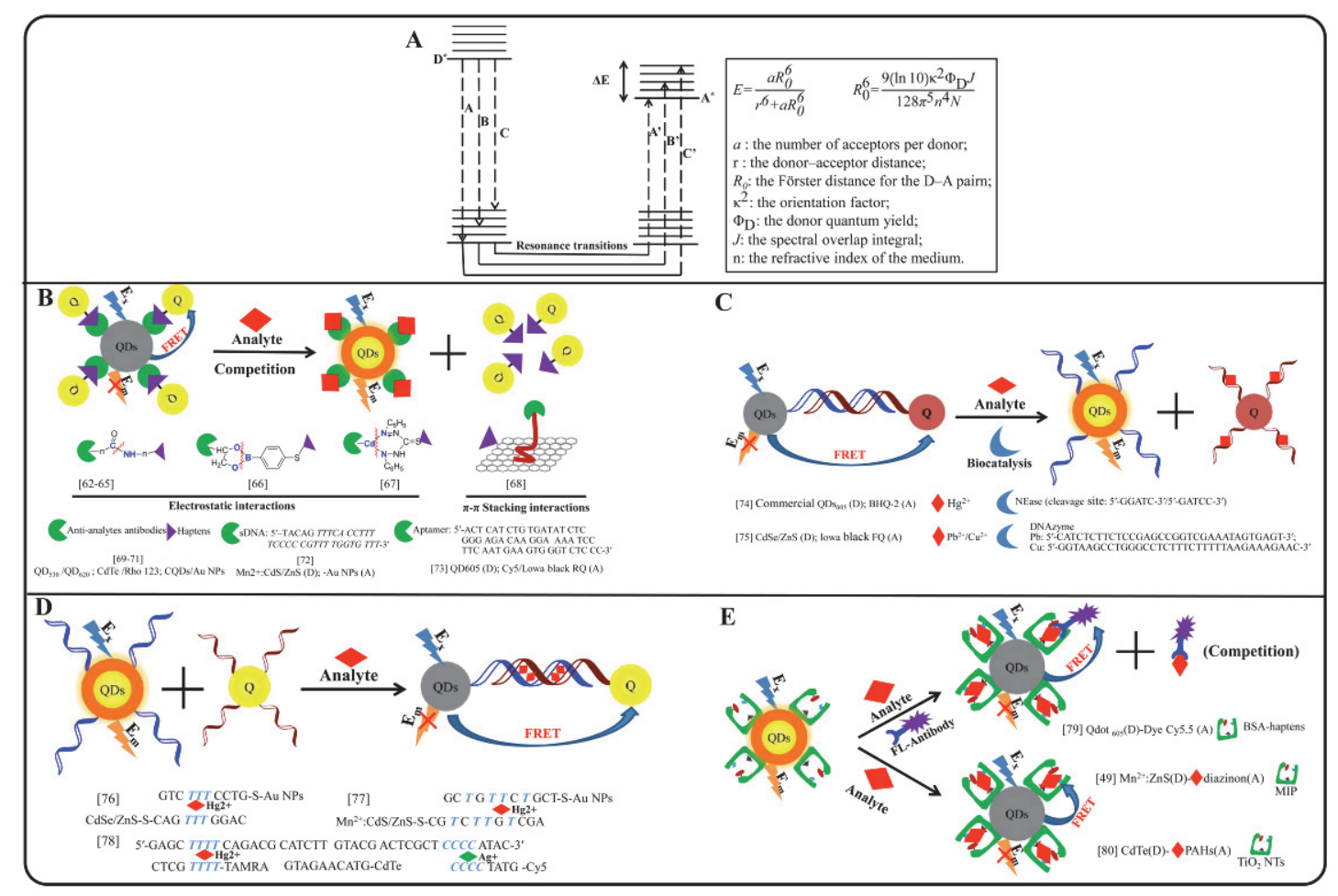

Figure 3 


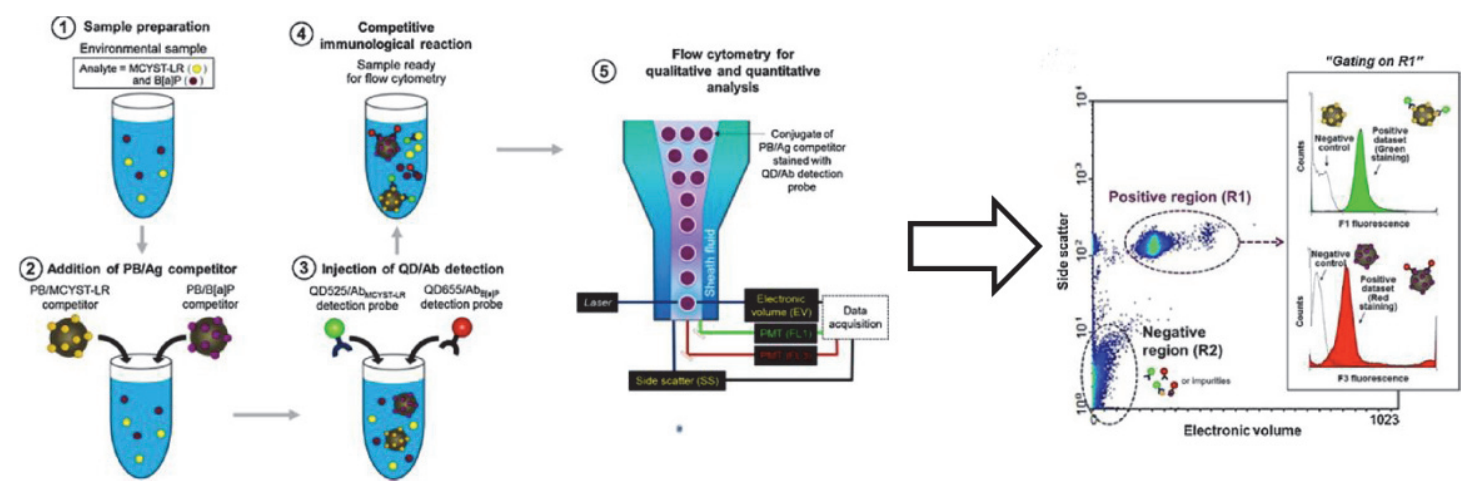

Figure 4 
Photoluminescent nanosensors capped with quantum dots for high-throughput determination of trace contaminants: Strategies for enhancing analytical performance

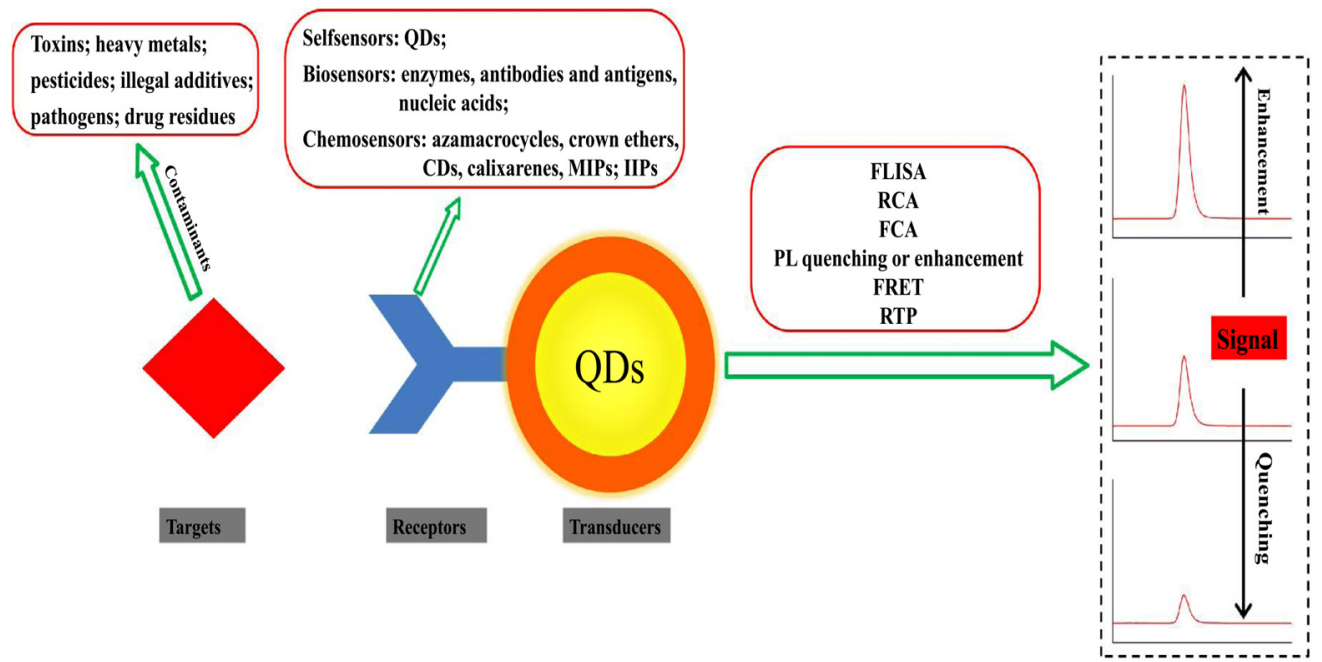

